\title{
Mass conservation above slopes in the Regional Atmospheric Modelling System (RAMS)
}

\author{
A. G. C. A. Meesters - L. F. Tolk - A. J. Dolman
}

Received: 2 January 2008 / Accepted: 30 April 2008 / Published online: 27 May 2008

(C) The Author(s) 2008

\begin{abstract}
This paper examines the mass balance in calculations with the Regional Atmospheric Modelling System (RAMS). An error is pointed out that concerns the calculation of the surface fluxes on slopes. This error affects all the prognostic variables in RAMS when sloping terrain is involved. Here we explain how the error can be corrected. To study the impact of the error, we compared simulations with the uncorrected and corrected model. The model contains $\mathrm{CO}_{2}$ transport, and online mass balance calculations were performed for this tracer. Without correction, effective surface $\mathrm{CO}_{2}$-fluxes on mountain slopes were found to be enhanced under certain common conditions to several times the parameterized fluxes. Neglecting this error may cause substantial deviations in both forward and inverse model calculations. After the correction a very good closure of the mass balance is obtained. The correction also modifies the meteorological parameters, although the consequences were limited compared to the $\mathrm{CO}_{2}$-fluxes.
\end{abstract}

Keywords Carbon dioxide - Mass conservation · Mesoscale modeling · RAMS · Tracer transport

\section{Abbreviation \\ RAMS Regional Atmospheric Modelling System}

\section{Introduction}

The Regional Atmospheric Modelling System (RAMS) is used for many purposes. One of these purposes is the modeling of transport of $\mathrm{CO}_{2}$ [1-6], and of pollutants [7-13]. Such modeling requires a high degree of accuracy when used for inverse model calculations, in

\footnotetext{
A. G. C. A. Meesters ( $\varangle)$ - L. F. Tolk · A. J. Dolman

Department of Hydrology and Geo-Environmental Sciences, Faculty of Earth and Life Sciences,

VU University Amsterdam, De Boelelaan 1085, 1081 HV Amsterdam, The Netherlands

e-mail: antoon@meesters.geo.falw.vu.nl
} 
which the distribution of sources and sinks is inferred from concentration measurements and the (back) calculated transport. In particular, it is obvious that for $\mathrm{CO}_{2}$ (or any other non-reactive tracer species), the requirement of mass conservation should be satisfied.

RAMS has been in use since the early nineties [14]. However, it appears that until recently, the subject of mass balance in RAMS has not received sufficient attention.

Medvigy et al. [15] described a correction to RAMS which improved the mass conservation by two orders of magnitude. This was obtained by improving the calculation of the pressure field, or more precisely, the Exner function, and hence the wind field.

Recently, an inter-comparison of RAMS and other meteorological models has been performed, using observations in South West France from the CarboEurope Regional Experiment Strategy (CERES) performed in 2005 [16]. The results of the inter-comparison are described in Sarrat et al. [5].

The point of interest for the present contribution is that in the morning hours on the Pyrenees, a relatively steep mountain chain, the $\mathrm{CO}_{2}$ concentration calculated by RAMS was changing at a rate often far greater than could be expected from the prescribed local surface fluxes. This caused an elevated plume of air with a perturbed $\mathrm{CO}_{2}$ concentration that was subsequently advected to the surrounding flatter regions where it extended far above the atmospheric boundary layer. Hence, the simulated $\mathrm{CO}_{2}$-profile above the boundary layer did not match the observations obtained by profiling aircraft $[5,16]$. This mismatch was a reason for further investigation of the mass balance in RAMS.

We observed that the calculations contained an error that occurred primarily on sloping surfaces. The error occurred mainly at night, at the lee side of the mountains. An elaborate investigation was performed through detailed code checking and elimination of possible error sources to locate the fault in the model. Below we present the results of this investigation.

\section{Theory}

\subsection{Calculation of the horizontal diffusion in RAMS}

The error found in RAMS causing mass imbalance at sloping surfaces is related to the calculation of the horizontal flux divergence, which proceeds as follows. Figure 1 shows a cell projected onto the xz-plane, and the points to which the scalar fluxes are attached (the picture for the momentum fluxes is somewhat different, because of the staggered grid). The horizontal flux in x-direction, $F_{x}$, is given for the points $\mathrm{W}$ and $\mathrm{E}$ (the centers of the west and east face). The purpose is to find its contribution $\partial F_{x} / \partial x$ to the flux divergence at the cell center $\mathrm{C}$. If no slope is present, we have the usual relation

$$
\frac{\partial F_{x}}{\partial x}=\frac{F_{x, E}-F_{x, W}}{\Delta x}
$$

However, this relation no longer suffices if the cell is located above a slope, since in this case the points $\mathrm{W}$ and $\mathrm{E}$ are located at different heights. One way to describe the logic which leads to the algorithm in RAMS is as follows (we leave out unessential details such as the horizontal variation of $\Delta z$ ). The gradient, which is a volume average over the grid cell, can be expressed as an integral over the cell surface by using the (one-direction form of the) Divergence Theorem of Gauss [17]:

$$
\frac{\partial F_{x}}{\partial x}=\frac{1}{V} \iiint \frac{\partial F_{x}}{\partial x} \mathrm{~d} V=\frac{1}{V} \oiint F_{x}(\mathbf{n} \cdot \mathbf{i}) \mathrm{d} A .
$$


Fig. 1 Attachment points for variables on a model grid cell (projection on the xz-plane). $\mathrm{F}_{x}$ is the horizontal flux in the $x$ direction: Solid arrows indicate model values, dashed arrows indicate averages of model values. $\mathrm{S}_{x}$ is the slope angle for the $x$-direction

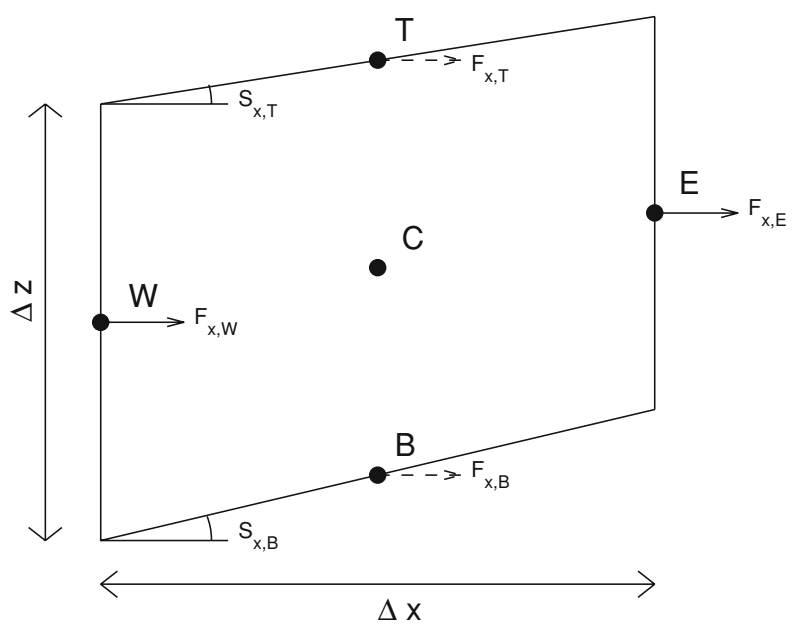

Herein, $V=\Delta x \Delta y \Delta z$ is the cell volume, $A$ the area, $\mathbf{n} \cdot \mathbf{i}$ the inner product of two unit vectors: $\mathbf{n}$ outward perpendicular to the cell surface, and $\mathbf{i}$ in the $x$-direction. The west and east face have contributions which yield again the right hand side of Eq. 1. The north and south face yield no contribution as $\mathbf{n} \cdot \mathbf{i}=0$. For the top and bottom face, $F_{x}(\mathbf{n} \cdot \mathbf{i})=-\overline{F_{x, T}} S_{x, T}$ and $+\overline{F_{x, B}} S_{x, B}$, in which $S_{x}$ is the slope of the grid level in $x$-direction, and $\overline{F_{x}}$ is the average value of $F_{x}$ for the top or bottom face (Fig. 1). This average is calculated from the values of $F_{x}$ on the W/E face of the cells above and below the concerned top and bottom face. Notice that $F_{x}$ is only given for the centers of standing W/E faces; averaging involves 4 points. Taking $\mathrm{d} A=\Delta x \times \Delta y$ for the corresponding surface, one obtains

$$
\frac{\partial F_{x}}{\partial x}=\frac{F_{x, E}-F_{x, W}}{\Delta x}+\frac{S_{x, B} \overline{F_{x, B}}-S_{x, T} \overline{F_{x, T}}}{\Delta z} .
$$

The contribution of $F_{y}$ is found by replacing $x$ with $y$, and west/east by south/north.

\subsection{An error in the mass balance}

The set up described above guarantees that scalars are conserved within the atmosphere above the surface, since each face between two cells has equal contributions (but with opposite signs) to each of the cells.

However, this logic does not hold at the bottom of the lowest cell which touches the surface. There the surface flux is of course important, but its calculation belongs to another part of the model dealing with vertical exchange. When the contributions of the horizontal fluxes are calculated, mass conservation requires that one replaces the usual $S_{x, B} \overline{F_{x, B}}$ and $S_{y, B} \overline{F_{y, B}}$ at the surface with zero.

RAMS, however, calculates these quantities at the surface just like they are dealt with for the internal faces between the cells. This is possible since RAMS uses a virtual atmospheric layer below the surface, which is needed for other computations, but is not appropriate here. As a consequence, the mass balance at the surface is distorted. The effective surface flux $F_{e f f}$ is modified with respect to the parameterized (correct) flux $F_{p a r}$, such that: 


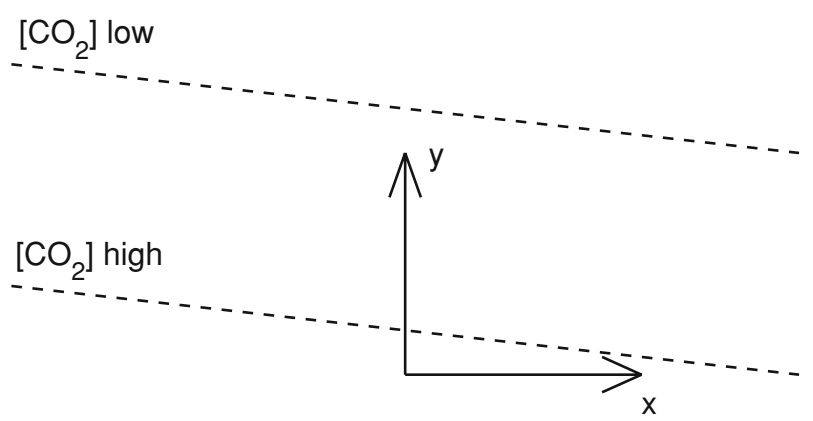

Surface

Fig. 2 Example of $\mathrm{CO}_{2}$ concentration contours above a slope, illustrating the relation between vertical and horizontal gradients and slope

$$
F_{\mathrm{eff}}=F_{\mathrm{par}}-S_{x, B} \overline{F_{x, B}}-S_{y, B} \overline{F_{y, B}} .
$$

This distortion actually occurs in the calculation of transport, not only of passive scalars, but also of temperature, moisture and momentum (friction).

It can be seen with some effort that, if along-slope gradients are unimportant compared to vertical gradients, the error will cause the effective surface flux to be too large. Let us e.g. consider (Fig. 2) a terrain sloping downward to the east $\left(S_{x}<0\right)$. To an upward vertical flux $\left(F_{\mathrm{par}}>0\right)$ corresponds a concentration decreasing with growing height, and accordingly $\partial \mathrm{c} / \partial \mathrm{x}<0$ (Fig. 2), so that the horizontal flux is $F_{x}=-K_{\text {hor }} \partial \mathrm{c} / \partial x>0$ (with $K_{\text {hor }}$ the horizontal diffusion coefficient). Consequently, by Eq. 4 the spurious term $-S_{x} \overline{F_{x, B}}$ yields a contribution that enhances the effective vertical flux at the surface. By similar reasoning for other cases, it is found that the spurious contributions enhance the effective vertical flux, in agreement with the numerical experiments.

\subsection{Correction of the error}

The error is corrected by setting the product of the horizontal flux and the slope to zero at the surface. This product is contained in RAMS (with a multiplication factor) in arrays called "vc1da", which are assigned in loops in four different subroutines, all of them contained in file "rgrad.f90". Since the first model layer is a virtual level, the lowest atmospheric level is the second vertical layer in the model. A complication is that the subroutines involved are called not only to calculate horizontal divergences, but also to calculate horizontal gradients. In the latter case, the existing assignment at the surface is intentional. So we have added after each assigning loop, the line "if(optyp .ne. 'GRADNT') vc1da(2)=0”. Addition of these four identical lines constitutes the entire correction.

\section{Model set up}

We performed simulations with the primary goal to illustrate that the impact of the error can be quite significant under certain conditions. The set up is the same for both simulations 
presented below, except that one was performed without, and one with the correction described in Sect. 2.3.

BRAMS-3.2 (RAMS including modifications by CPTEC/INPE-Brazil) is used. In this version the Medvigy et al. [15] correction (see above) has already been applied.

Only one grid is used in these simulations. Horizontally, there are $40 \times 40$ grid points, with a horizontal grid distance of $5 \mathrm{~km}$. The coordinates are terrain-following. Vertically, there are 41 levels, the highest level is at $17.5 \mathrm{~km}$. The grid distance is $60 \mathrm{~m}$ at the surface. The LEAF-3 surface module, the Mellor-Yamada turbulence scheme and the Mahrer-Pielke radiation scheme are used (see the Technical Description [18]).

For efficiency reasons, a simple and highly idealized set up has been used for the orography. It consists of an axi-symmetric mountain in the center, with a height of $2 \mathrm{~km}$ and a radius of $50 \mathrm{~km}$ (Fig. 3). The vegetation consists of short grass on loamy sand.

The latitude is $50^{\circ} \mathrm{N}$, the day corresponds to a cloudless day in summer. The initial temperature is $25^{\circ} \mathrm{C}$ at sea level, with a lapse rate $0.005 \mathrm{~K} / \mathrm{m}$ up to about $10 \mathrm{~km}$. The initial wind is eastward, speed $5 \mathrm{~m} \mathrm{~s}^{-1}$ (less at the surface). A zero-gradient condition is applied at the lateral boundaries.

The $\mathrm{CO}_{2}$-field is initialized at $370 \mathrm{ppm}$ everywhere. The $\mathrm{CO}_{2}$ flux at the surface does not depend on location, and is specified as a diurnal sine wave with top values of $-20 \mu$ mol m $\mathrm{m}^{-2} \mathrm{~s}^{-1}$ at $1200 \mathrm{UT}$, and $+20 \mu \mathrm{mol} \mathrm{m}^{-2} \mathrm{~s}^{-1}$ at $2400 \mathrm{UT}$.

RAMS as such does not contain tools to monitor mass balance, so these were built in. In doing so, source codes kindly supplied by D. Medvigy (personal communication) were of great use. For the air density we use the background density, in accordance with the logic used by RAMS in the transport calculations. We express the rate of change of $\mathrm{CO}_{2}$ content in the model as the tendency of the total mass, divided by the area of the computation domain. This differs from the normalization used by Medvigy et al. [15], which would have been too coarse for the present investigation. The computation domain for the mass balance monitoring is the model domain with the lateral zone of 3 grid cells excluded.

\section{Results}

\subsection{Results for $\mathrm{CO}_{2}$ without and with correction}

The simulations start at $0600 \mathrm{UT}$, and proceed for $30 \mathrm{~h}$. The solar time roughly equals the universal time. After about $26 \mathrm{~h}$ of simulation, the difference between the results of the two runs reaches its maximum. Transects of the $\mathrm{CO}_{2}$-concentration for this time are shown in Figs. 3 (uncorrected model) and 4 (corrected model).

In Fig. 3, above the plain a depleted residual boundary layer of about $1 \mathrm{~km}$ height is observed, which has developed at daytime (first $12 \mathrm{~h}$ ). Close to the surface there is the enriched nocturnal layer which has developed in the last night. These phenomena are as expected, but unexpected phenomena emerge on the mountain. In its wake, a zone which is strongly enriched in $\mathrm{CO}_{2}$ develops during the night.

In Fig. 4, the plume with $\mathrm{CO}_{2}$-enriched air has become much weaker. This shows that the features noted in Fig. 3 on the lee-side of the mountain, were an artifact caused by the mass imbalance in the uncorrected model. These phenomena will be discussed further in Sect. 4.2. However, first a look at the mass balance is needed. 


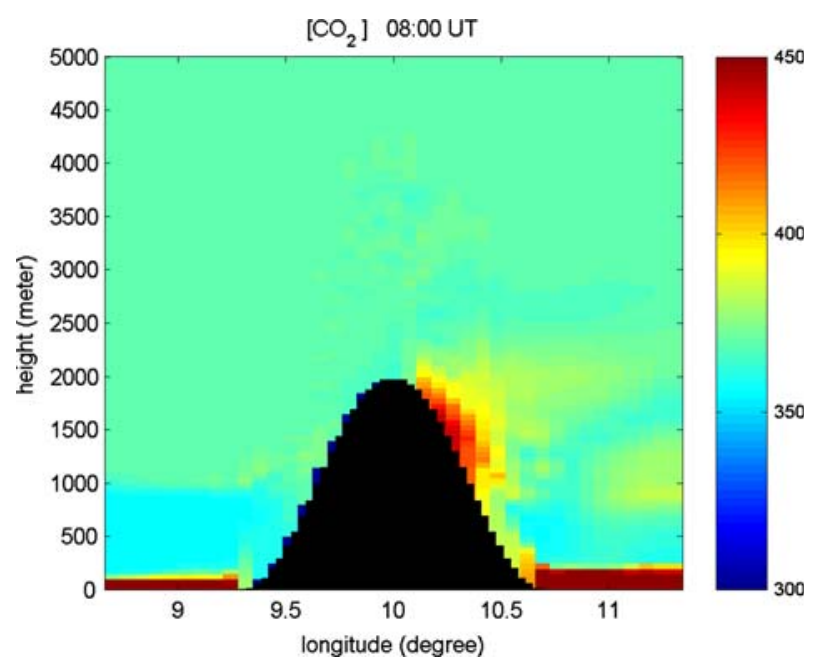

Fig. 3 Uncorrected model: $\mathrm{xz}$ transect of the $\mathrm{CO}_{2}$ concentration at $0800 \mathrm{UT}$ (morning)

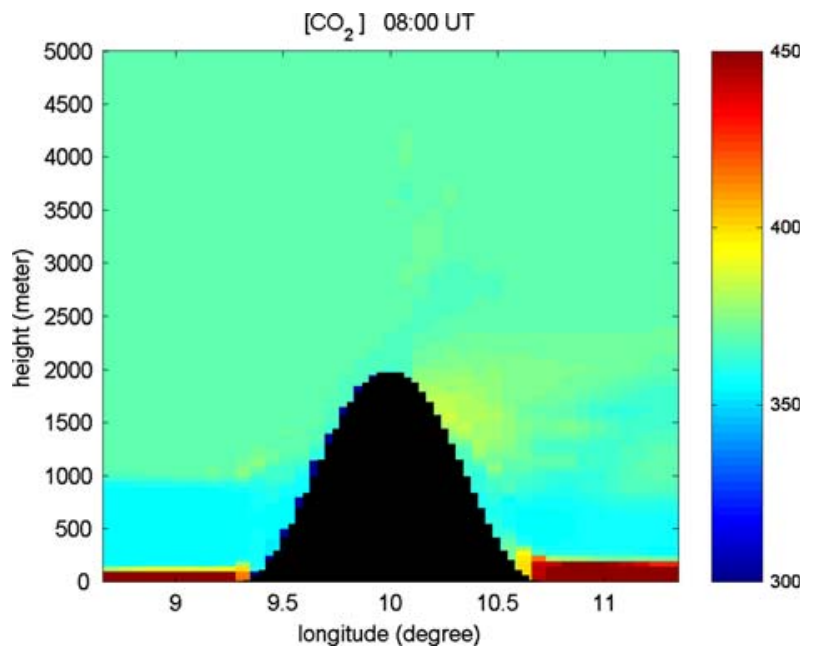

Fig. 4 The same, corrected model

During the subsequent daytime, the fluxes produced by the uncorrected model on the slopes become normal, but the already produced spurious plume is advected away from the mountain and is still clearly visible around noon (not shown).

Online mass balance calculations were added to the model, as explained in Sect. 3. Time series were calculated for the inflow of $\mathrm{CO}_{2}$, both "expected" (from fluxes at the boundaries), and "effective" (from volume integrals). This was done for advection and diffusion separately.

For advection (not shown), the effective inflow does well match the expected inflow. This confirms the correction described by Medvigy et al. [15].

Figure 5 shows the results for the diffusion step for the uncorrected model. The expected rate of change is calculated from the surface flux plus the flux by horizontal diffusion at the 
Fig. 5 Uncorrected model: Time series of the $\mathrm{CO}_{2}$ mass change rate at the diffusion step. Dashed line: expected, solid line: effective rate

Fig. 6 The same, for the corrected model. The two curves are practically indiscernible, as it should
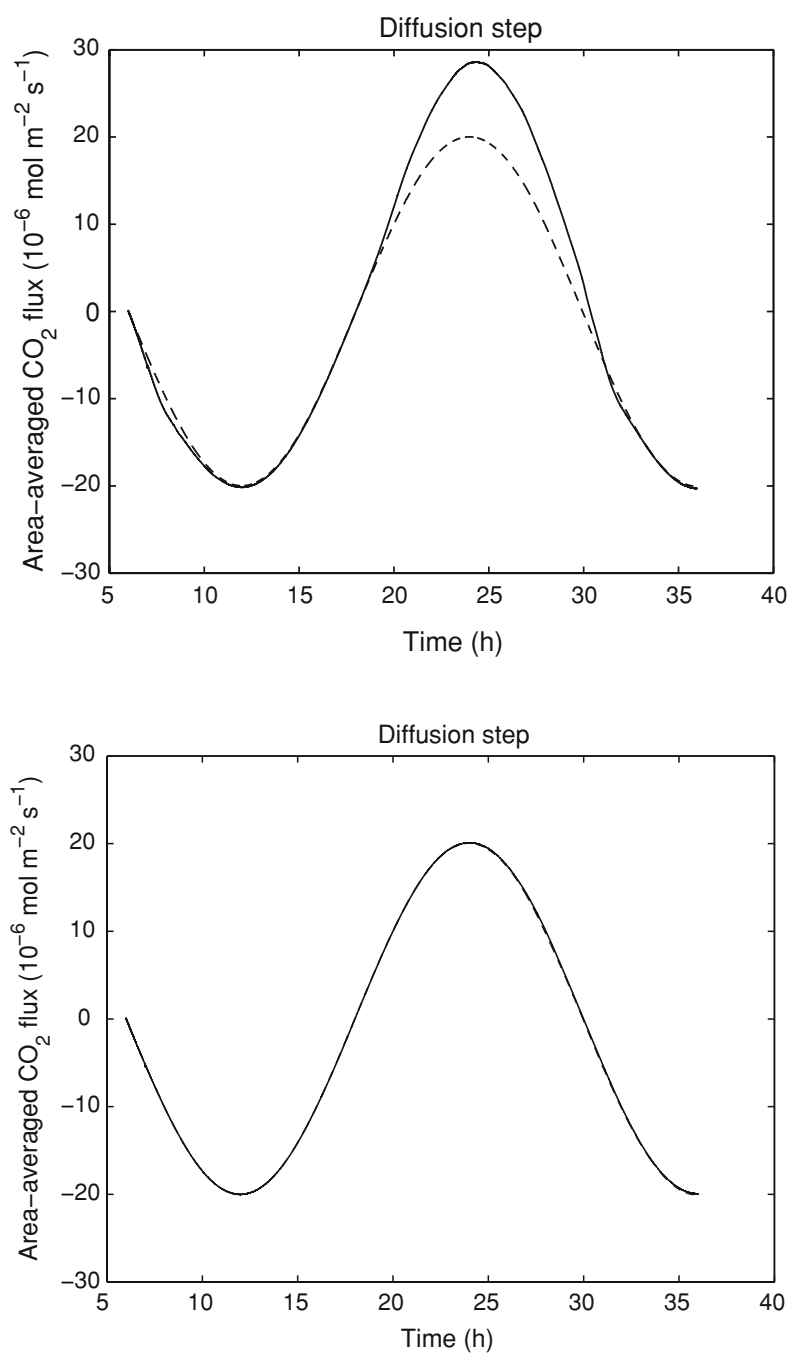

lateral boundaries (but the latter contribution is small). Results are expressed as area-averaged fluxes in $\mu \mathrm{mol} \mathrm{m} \mathrm{m}^{-2} \mathrm{~s}^{-1}$, since we are interested in inversion calculations which infer surface fluxes from the evolution of concentrations. The two curves have a strong mismatch at night, confirming that the plume of Fig. 3 is caused by the error in the mass balance. During daytime the error is much smaller.

Figure 6 shows the time series of the expected and effective inflow (diffusion step only) after the correction. The mismatch has disappeared now, showing that the correction is successful.

Simulations have also been done for flat terrain. As could be expected no mass balance error was ever detected even with the uncorrected model. It follows that there is no reason to distrust uncorrected calculations performed for flat terrains, and that the mass balance error is confined to mountainous areas. Since these occupy in the present case less than three tenth of the area over which the fluxes shown in Figs. 5 and 6 are averaged, the effective flux on 
the slopes has to be locally several times the parameterized flux to explain the magnitude of the error which is seen in Fig. 5.

\subsection{Explanation of the phenomena due to mass imbalance}

To understand how mass imbalance leads to the features in Fig. 3, and why these are restricted to the lee side, a few remarks may be helpful. During the night, the flow at the lee side becomes very weak, due to the screening effect of the mountain. Hence a strongly layered $\mathrm{CO}_{2}$-field can develop on the lee slope. So $\partial c / \partial x$ becomes large there. The horizontal flux $F_{x}=-K_{\text {hor }} \partial c / \partial x$ becomes large too, as $K_{\text {hor }}$ is not suppressed by strong static stability (it only depends on the horizontal wind strain, Anonymous [18]). This causes a strong flux amplification above the slope by Eq. 4, causing even stronger gradients and stronger amplification (positive feedback). The amplification is at its peak at about midnight (Fig. 5). During the late night katabatic flow starts to develop, causing gradual concentration mixing and a weaker imbalance (Fig.5), but $\mathrm{CO}_{2}$ keeps accumulating at the surface until about $0800 \mathrm{UT}$ to which Fig. 3 refers. Elsewhere, stronger winds make $\partial c / \partial x$ much weaker so that the flux amplification is limited.

After about 0800 UT the $\mathrm{CO}_{2}$-gradients disappear due to convection and also to anabatic wind. Hence the distorting terms in Eq. 4 become negligible, which is confirmed by Fig. 5.

\subsection{Effect of the correction on meteorological variables}

The differences between simulations without and with correction have also been determined for the meteorological variables. The inspection concentrated on the values at reference height $(35 \mathrm{~m})$. All these variables have pronounced spatial patterns, either because of the non-constant initial profiles (temperature, mixing ratio), or because of the obstruction caused by the mountain (wind). We found that the patterns are only slightly modified when no correction is applied. For temperature and mixing ratio, the differences are at most about $0.5^{\circ}$ and $0.5 \mathrm{~g} \mathrm{~kg}^{-1}$, reached in the early morning. For wind, the differences consist mainly in a slight location-shift of the (complicated) spatial pattern over the mountain.

It can be concluded that the effect of the reported error for the meteorological variables is overall small, although detectable. This implies that it is safer to work with the corrected model, whenever sloping terrain is involved.

\section{Conclusions}

It has been shown that effective surface fluxes of scalars, as calculated by RAMS, differ from the parameterized fluxes over sloping surfaces. The difference depends on the slope angle and on the horizontal gradients (Fig. 2) of scalars. If concentration variation along the slope is unimportant, the flux is in general enhanced. Under certain conditions (strong slope, weak wind, nocturnal cooling) the effective flux of $\mathrm{CO}_{2}$ may locally approach several times the parameterized value. Relatively calm conditions favor the formation of strong horizontal gradients and hence of strong horizontal diffusive fluxes $F_{x}$ and $F_{y}$, enhancing the error according to Eq. 4.

The origin of this problem is the way in which horizontal diffusion is corrected for the presence of a slope: the virtual horizontal flux at the surface is translated to a real mass flux through this surface, whereas the mass flux should remain unaltered at this point of the calculation. Accordingly, the error is easily repaired. 
The mass-imbalance which was encountered when reproducing CERES observations (see introduction), disappeared after application of the correction (not shown).

It is obvious that the error leads to problems with the modeling of the transport of $\mathrm{CO}_{2}$ and other long-living constituents, especially when inversion calculations are intended. In the latter case, the assessment of surface fluxes can become totally error-dominated for sloping terrains. The error also concerns the calculation of the sensible and latent heat flux, and the wind friction at sloping surfaces. For the cases investigated here, these differences appeared small in comparison to the already existing local variations, but they are still detectable. Apparently, the error in the fluxes at the surface can cause changes for all prognostic variables. This implies that, wherever sloping terrains are important, the use of the corrected version of RAMS has to be recommended.

Acknowledgements We thank Reinder J. Ronda for his help with getting started with RAMS including $\mathrm{CO}_{2}$, David Medvigy for kindly providing us with mass balance calculation codes, Robert L. Walko for checking the reported error detection, and Wouter Peters for improvements of the manuscript. This research was executed as part of the CarboEurope Integrated Project, project no. GOCE-CT2003-505572, supported by the European Commission.

Open Access This article is distributed under the terms of the Creative Commons Attribution Noncommercial License which permits any noncommercial use, distribution, and reproduction in any medium, provided the original author(s) and source are credited.

\section{References}

1. Nicholls ME, Denning AS, Prihodko L, Vidale PL, Baker I, Davis K, Bakwin P (2004) A multiple-scale simulation of variations in atmospheric carbon dioxide using a coupled biosphere-atmospheric model. J Geophys Res-Atmos 109(D18):D18117

2. Lu LX, Denning AS, da Silva-Dias MA, da Silva-Dias P, Longo M, Freitas SR, Saatchi S (2005) Mesoscale circulations and atmospheric $\mathrm{CO}_{2}$ variation in the Tapajos Region, Para, Brazil. J Geophys ResAtmos 110(D21):D21102

3. Wang JW, Denning AS, Lu LX, Baker IT, Corbin KD, Davis KJ (2007) Observations and simulations of synoptic, regional, and local variations in atmospheric $\mathrm{CO}_{2}$. J Geophys Res-Atmos 112(D4):DO4108

4. Van der Molen MK, Dolman AJ (2007) Regional carbon fluxes and the effect of topography on the variability of atmospheric $\mathrm{CO}_{2}$. J Geophys Res 112:D01104

5. Sarrat C, Noilhan J, Dolman AJ, Gerbig C, Ahmadov R, Tolk LF, Meesters AGCA, Hutjes RWA, Ter Maat HW, Pérez-Landa G, Donier S (2007) Atmospheric $\mathrm{CO}_{2}$ modeling at the regional scale: an intercomparison of 5 meso-scale atmospheric models. Biogeosciences 4:1115-1126

6. Tolk LF, Meesters AGCA, Dolman AJ, Peters W (2008) Modelling representation errors of atmospheric $\mathrm{CO}_{2}$ concentrations at a regional scale. Atmos Chem Phys Discuss 8:3287-3312

7. Audiffren N, Buisson E, Cautenet S, Chaumerliac N (2004) Photolytic impact of a stratocumulus cloud layer upon the chemistry of an offshore advected plume of pollutants during the NARE 1993 intensive experiment: a numerical study. Atmos Res 70:89-108

8. Taghavi M, Cautenet S, Foret G (2004) Simulation of ozone production in a complex circulation region using nested grids. Atmos Chem Phys 4:825-838

9. Taghavi M, Cautenet S, Arteta J (2005) Impact of a highly detailed emission inventory on modeling accuracy. Atmos Res 74:65-88

10. de Freitas ED, Martins LD, Dias PLD, Andrade MD (2005) A simple photochemical module implemented in RAMS for tropospheric ozone concentration forecast in the metropolitan area of Sao Paulo, Brazil: coupling and validation. Atmos Environ 39:6352-6361

11. Foret G, Flamant C, Cautenet S, Pelon J, Minvielle F, Taghavi M, Chazette P (2006) The structure of the haze plume over the Indian Ocean during INDOEX: tracer simulations and LIDAR observations. Atmos Chem Phys 6:907-923

12. Wang J, Christopher SA, Nair US, Reid JS, Prins EM, Szykman J, Hand JL (2006) Mesoscale modeling of Central American smoke transport to the United States: 1. "Top-down" assessment of emission strength and diurnal variation impacts. J Geophys Res-Atmos 111(D5):D05S17 
13. Arteta J, Cautenet S, Taghavi M, Audiffren N (2006) Impact of two chemistry mechanisms fully coupled with mesoscale model on the atmospheric pollutants distribution. Atmos Environ 40:7983-8001

14. Pielke RA, Cotton WR, Walko RL, Tremback CJ, Lyons WA, Grasso LD, Nicholls ME, Moran MD, Wesley DA, Lee TJ, Copeland JH (1992) A comprehensive meteorological modeling system-RAMS. Meteorol Atmos Phys 49:69-91

15. Medvigy D, Moorcroft PR, Avissar R, Walko RL (2005) Mass conservation and atmospheric dynamics in the Regional Atmospheric Modeling System (RAMS). Environ Fluid Mech 5:109-134

16. Dolman AJ, Noilhan J, Durand P, Sarrat C, Brut A, Piguet B, Butet A, Jarosz N, Brunet Y, Loustau D, Lamaud E, Tolk L, RondaR, Miglietta F, Gioli B, Magliulo V, Esposito M, Gebrig C, Körner S, Glademard P, Ramonet M, Ciais P, Neininger B, Hutjes RWA, Elbers JA, Macatangay R, Schrems O, Pérez-Landa G, Sanz MJ, Scholz Y, Facon G, Ceschia E, Beziat P (2006) The CarboEurope regional experiment strategy. Bull Am Meterol Soc 87:1367-1379

17. Anton H (1995) Calculus with analytic geometry. 5edn. Wiley, New York etc

18. Anonymous RAMS. The Regional Atmospheric Modeling System. Technical Description (Draft). www. atmet.com 